\title{
A stainless-steel mandrel for slumping glass $x$-ray mirrors
}

Mikhail V. Gubarev ${ }^{1}$, Stephen L. O'Dell ${ }^{1}$, William D. Jones ${ }^{1}$, Thomas J. Kester ${ }^{1}$, Charles W. Griffith ${ }^{1}$, William W. Zhang ${ }^{2}$, Timo T. Saha², Kai-Wing Chan ${ }^{2}$

${ }^{1}$ NASA Marshall Space Flight Center (MSFC), Huntsville, AL 35812

2 NASA Goddard Space Flight Center (GSFC), Greenbelt, MD 20771

\section{ABSTRACT}

We have fabricated a precision full-cylinder stainless-steel mandrel at Marshall Space Flight Center. The mandrel is figured for a 30-cmdiameter primary (paraboloid) mirror of an $840-\mathrm{cm}$ focal-lengthWolter-1 telescope. We have developed this mandrel for experiments in slumping-thermal forming at about $600^{\circ} \mathrm{C}$-of glass mirror segments at Goddard Space Flight Center, in support of NASA's participation in the International X-ray Observatory (IXO). Precision turning of stainless-steel mandrels may offer a low-cost alternative to conventiona figuring of fused-silica or other glassy forming mandrels. We report on the fabrication, metrology, and performance of this first mandrel; then we discuss plans and goals for stainless-steel mandrel technology.

\section{INTERNATIONAL X-RAY OBSERVATORY}

The International $X$-ray Observatory (IXO), next-generation astronomical X-ray Mission, requires extremely large collecting area (3 square meters of effective area at $1 \mathrm{keV}$ and 1 square meter at $6 \mathrm{keV}$ ) combined with good angular resolution (5 arcsec half power diameter) in order to achieve unprecedented sensitivities for the study of the high-z Universe and for high-precision spectroscopy of bright X-ray sources. Slumping glass technology is one of the fabrication techniques considered for producing the $x$-ray mirror segments for a single large x-ray mirror assembly. This mirror fabrication approach requires massive number of the forming mandrels. Stainless-steel mandrels may offer a low-cost alternative to conventional figuring of fused-silica or other glassy forming mandrels.

\section{Stainless Steel Mandrel} Goal:

Find commercially available material applicable for manufacturing of the forming mandrels to significantly reduce cost of the glass replication process

\section{Mandrel description}

$-155.080 \mathrm{~mm}$ intersection plane radius

$-304.8 \mathrm{~mm}$ overall length (12.000 inches)

$-200 \mathrm{~mm}$ optical length (50 $\mathrm{mm}$ zone at each end for polishing overstroke)

Performance prediction requirement -15 arc seconds (HPD)

Material: 304L Stainless Steel

$-18-20 \% \mathrm{Cr}, 8-12 \% \mathrm{Ni}$

$-0.03 \% \mathrm{C}, 1 \% \mathrm{Mn}, 1 \% \mathrm{Si}, 0.045 \% \mathrm{P}, 0.03 \% \mathrm{~S}, 0.1 \%$ other
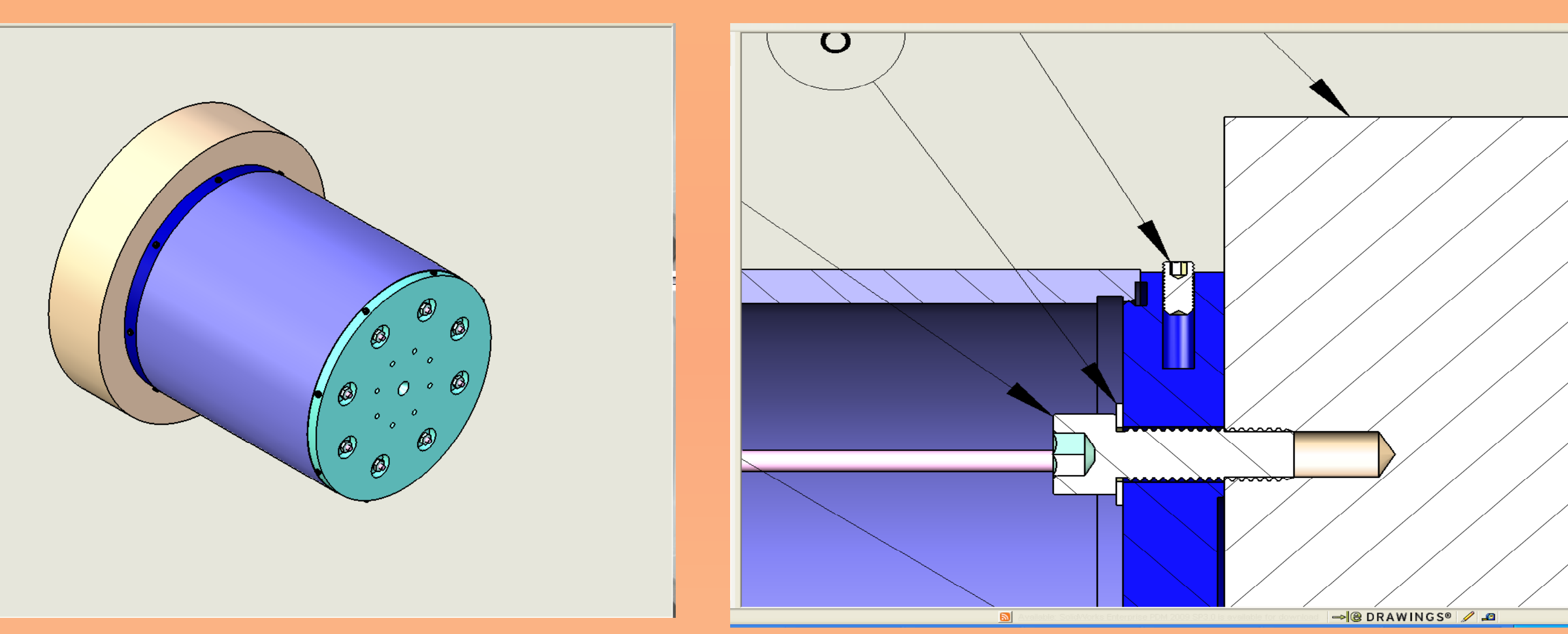

Mandrel support design

\section{Mandrel Fabrication}

$>$ Rough machining - Heat Treatment - Precise machining - Initial Precision turning - Axial Figure Metrology - Final Precision Turning - Polishing - Final Metrology $>$ Design of the support structures for machining, turning and polishing - Precision fit.

Thickness of the mandrel was set to $1 \mathrm{~cm}$ based on thermal considerations.

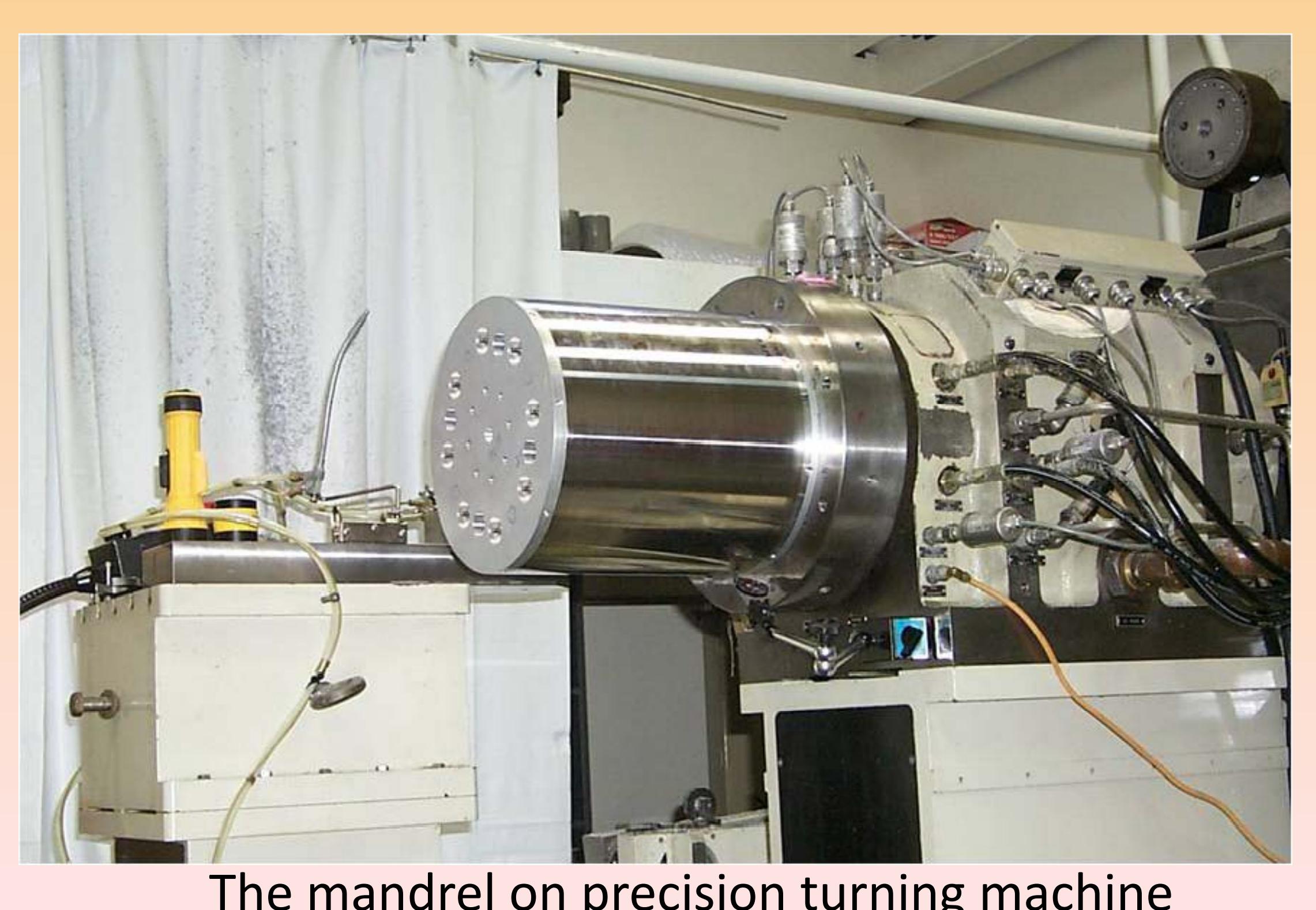

\section{Mandrel Fabrication (cont.)}

Pre-machining and precise turning

The mandrel was stress relieved at $650^{\circ} \mathrm{C}$ for one hour. The stress relieving temperature is much lower than annealing temperature $\left(1010\right.$ to $\left.1120^{\circ} \mathrm{C}\right)$, so grain growth should not be a

Rough machining went fine, but the mandrel was warped after heat treatment. Contractor has performed the precise machining:

$>$ "Free standing" mandrel is out of roundness;

Mandrel was turned on inside to make it to conform to the end rings better;

All mandrel assemblies were done at the Circularity Test Stand.

\section{Polishing:}

$>$ The hardened steel layer has appeared during initial polishing. The mandrel was precision grinded.

$>$ At the point of final polishing pull-outs became visible (possibly the result of the precision turning)

$>$ The mandrel was precision grinded again

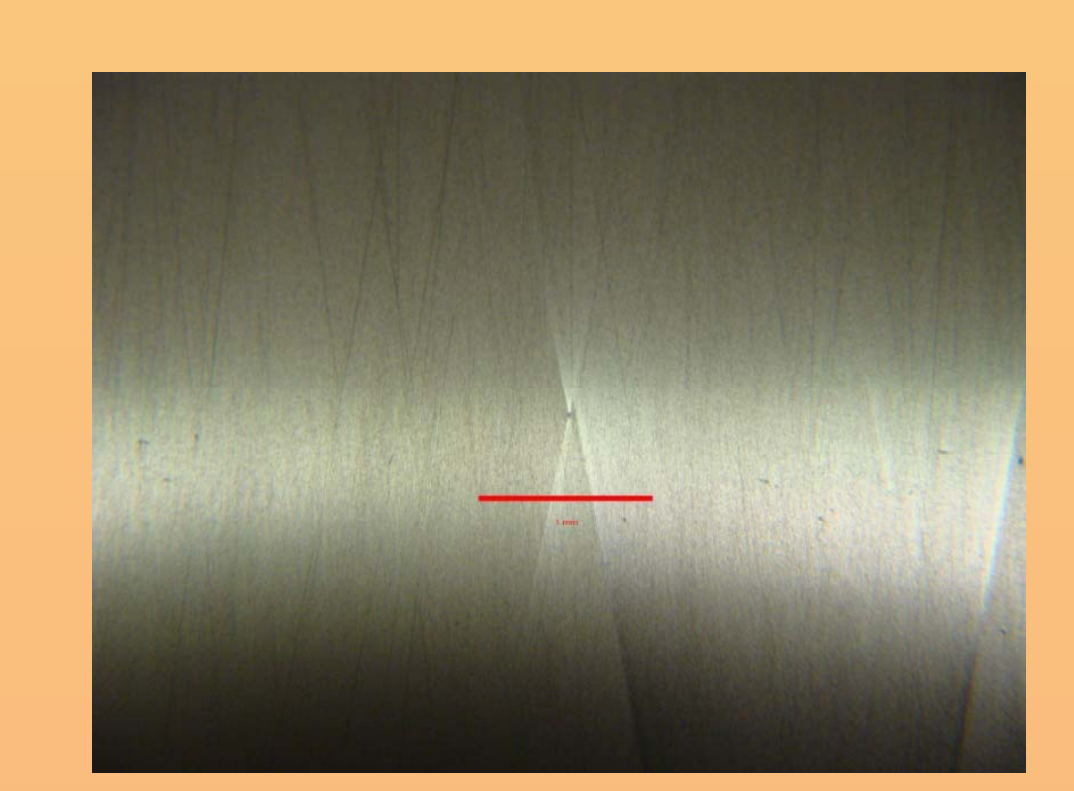

$>$ The mandrel is polished to $45 \mathrm{~A} \mathrm{rms}$

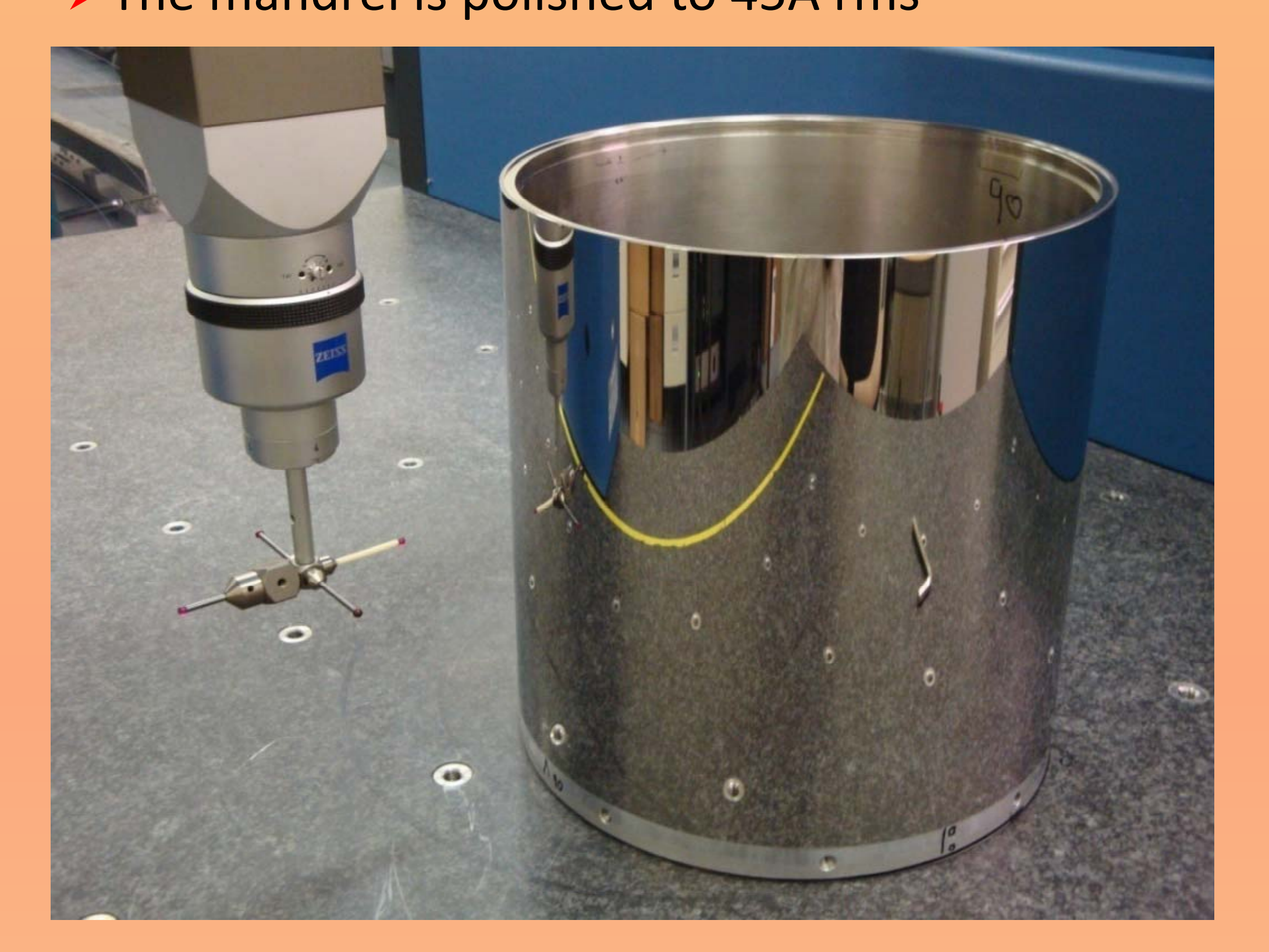

Stainless Steel Mandrel at Coordinate

Measuring Machine

\section{Metrology and Analysis}

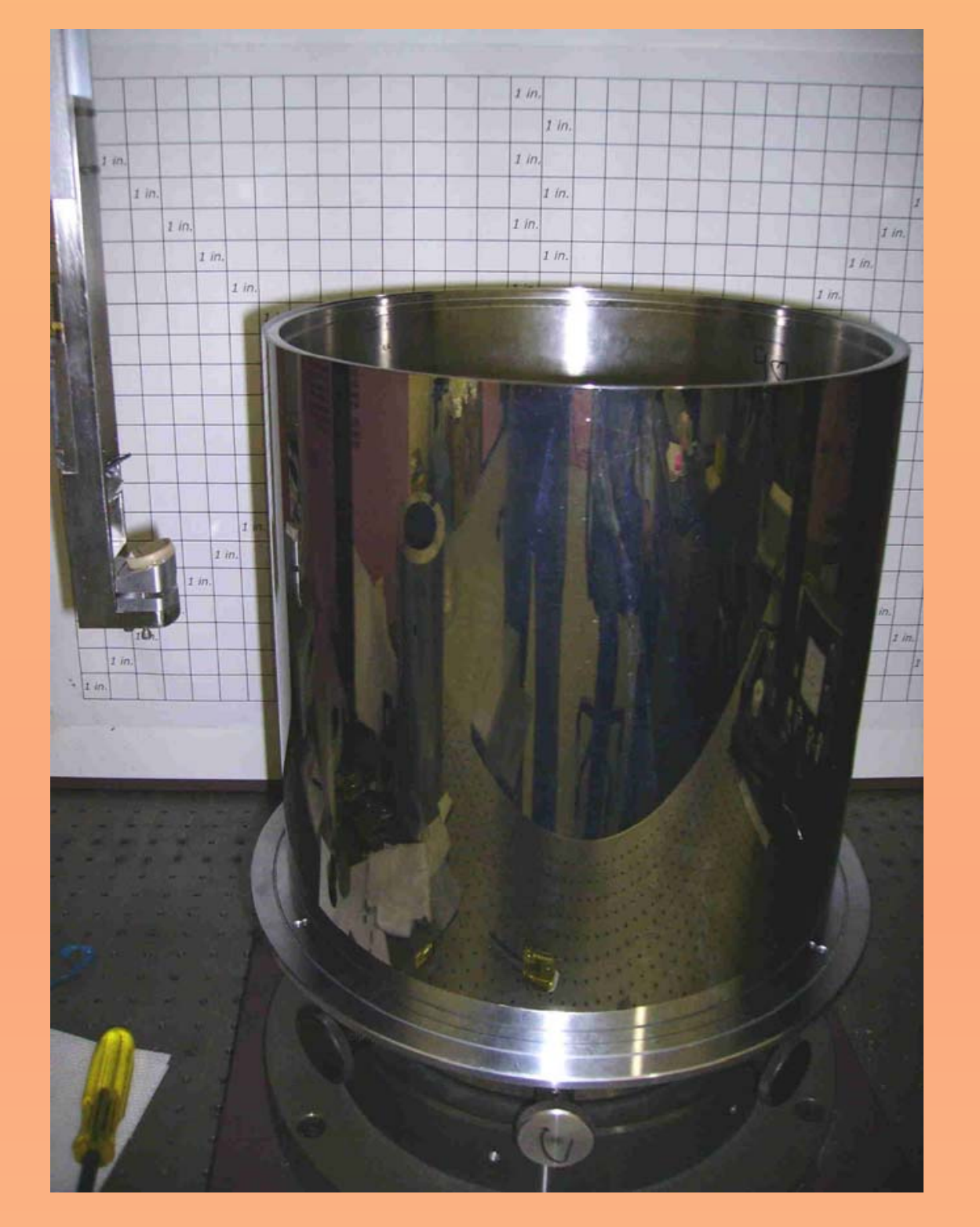

Circularity Test Stand - for azimuthal variations of radius and cone angle

Vertical Long Trace Profilometer - for axial slope deviations

$>$ Coordinate Measuring Machine - for absolute radius and mean cone angle

Predicted Angular resolution (HPD), 2 reflections
\begin{tabular}{|l|cccccccc|c|}
\hline Meridian & $\mathbf{0}^{\circ}$ & $\mathbf{4 5}^{\circ}$ & $\mathbf{9 0}^{\circ}$ & $\mathbf{1 3 5}^{\circ}$ & $\mathbf{1 8 0}^{\circ}$ & $\mathbf{2 2 5}$ & $\mathbf{2 7 0 ^ { \circ }}$ & $\mathbf{3 1 5}$ & All 8 \\
\hline Axial $\mathrm{HPD}_{2}["]$ & 6.08 & 6.49 & 7.23 & 4.85 & 5.07 & 5.05 & 7.24 & 6.77 & 6.13 \\
\hline${\text { Cone } \mathrm{HPD}_{\mathrm{G} 2}["]}$ & 6.39 & 1.49 & 3.93 & 1.25 & 2.57 & 4.93 & 6.80 & 3.75 & 7.28 \\
\hline $\begin{array}{l}\text { Total } \mathrm{HPD}_{2} \\
\text { ["] }\end{array}$ & $\mathbf{8 . 8 3}$ & $\mathbf{6 . 6 6}$ & $\mathbf{8 . 2 3}$ & $\mathbf{5 . 0 1}$ & $\mathbf{5 . 6 8}$ & $\mathbf{7 . 0 6}$ & $\mathbf{9 . 9 4}$ & $\mathbf{7 . 7 4}$ & $\mathbf{9 . 5 2}$ \\
\hline
\end{tabular}

Surface Passivation
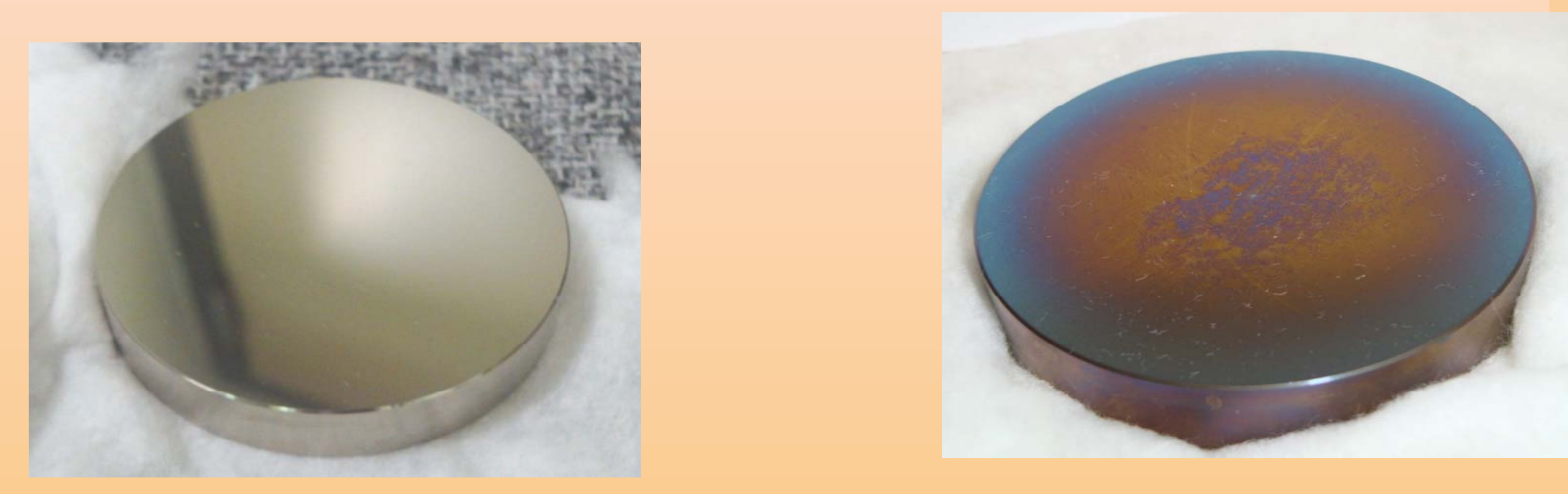

- Surface of SS coupon degraded during thermal cycling - A surface passivation study has been performed. Two techniques have been tested: the electro-chemical passivation and nitric acid passivation.

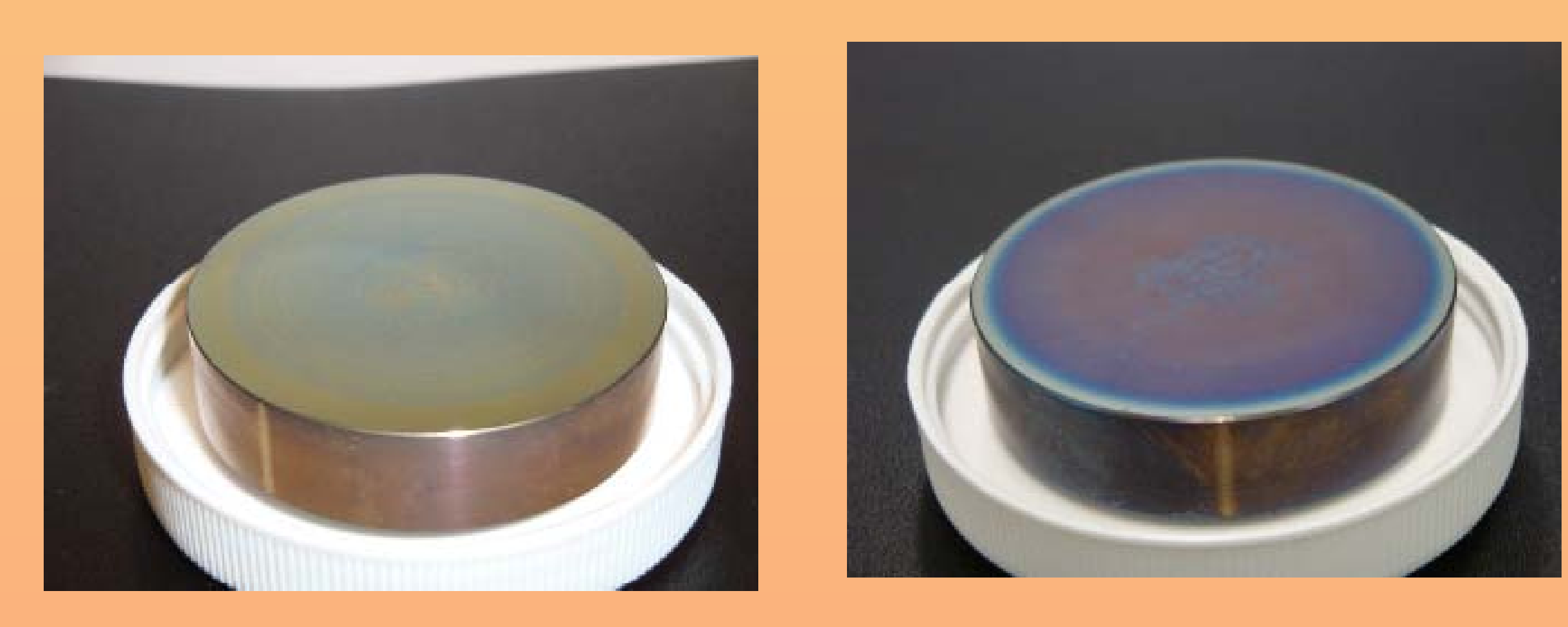

Results:

Nitric acid passivated stainless steel coupon (left photo) - the surface roughness degraded from 46 to $168 \mathrm{~A}$ after the heat treatment;

Electrochemically passivated stainless steel coupon (right photo) - the surface roughness degraded from 23 to $1068 \mathrm{~A}$ after the heat treatment.

\section{Future Plans}

Thermally cycle the mandrel. Perform full metrology on the heat treated mandrel to characterize possible changes in mandrels figure, circularity and surface roughness;

$>$ Resume fabrication process study with coupons in order to define an ideal stainless steel for mandrel production;

$>$ Produce hyperbolic mandrel to match the primary mandre 